\title{
Wolfgang Seeger, Endoscopic and microsurgical anatomy of the upper basal cisterns
}

\author{
150 pp, 60 Figures, Hardcover, ISBN: 978-3-211-77034-4, Springer
}

\author{
Nicolas de Tribolet
}

Received: 22 October 2009 / Accepted: 28 October 2009 /Published online: 24 November 2009

(C) Springer-Verlag 2009

This is yet another beautifully illustrated book on anatomy by Prof Seeger. The text is separated from the figures, which I regret because it makes the book difficult to consult. One has to constantly move from text to figures.

Part 1, GENERAL ASPECTS, deals with the cranial base and its landmarks, craniobasal and cerebrobasal structures close to the basal cisterns, architecture of basal cisterns, and extradural extensions of the basal cisterns

Part 2, SPECIAL ASPECTS, contains the following cisterns: Cisterna laminae terminalis, Cisterna valleculae (carotid cistern), Cisterna fossae lat (Sylvii), Cisterna chiasmatis, Cisterna interpeduncularis, Cistra ambiens, and Cisterna cruralis.

Part 3, SYNOPSIS, shows the relationships of cisterns to vessels and relationship of cranial nerves to intra- and extradural structures.
The figures, in black and white, are drawn by Prof Seeger's own hand in his very characteristic style. It is, however, difficult to use them practically for planning surgery. For example in Fig. 48, cistern interpenduncularis, adjacent cisterns, vessels, and cranial nerves, the cisternal walls are indicated with dots which make the figure crowded and difficult to understand. On the other hand, Fig. 35, 36, 37, and 38 clearly display arteries and perforators and their variations of the cistrna laminae terminalis. What I really missed are actual photographs of the anatomy as seen through the endoscope or the microscope corresponding to the drawings.

To sum up, this is a beautifully illustrated book which every neurosurgeon who owns the previous books of Prof Seeger (like myself) should have in his library, but its practical use is limited.

N. de Tribolet $(\square)$

Neurochirurgie, HUG,

1211 Geneva, Switzerland

e-mail: nicolas.detribolet@unige.ch

N. de Tribolet

University of Geneva,

Geneva, Switzerland 